\title{
The role of extensionists in Santa Catarina, Brazil, in the adoption and rejection of providing pain relief to calves for dehorning
}

\author{
M. J. Hötzel ${ }^{* 1}$ and J. N. Sneddon† \\ *Laboratório de Etologia Aplicada e Bem-Estar Animal, Universidade Federal de Santa Catarina, Rodovia Admar Gonzaga, 1346, Itacorubi, \\ Florianópolis, SC 88.034-001, Brazil \\ †The University of Western Australia, 35 Stirling Highway, Crawley, WA 6009, Australia
}

\section{ABSTRACT}

The majority of dairy calves around the world are dehorned with methods that cause them pain and distress. In some dairy production systems, extensionists may influence dehorning practices used on farm through their advisory and knowledge-transfer role. The aims of this study were to investigate Brazilian extensionists' knowledge, beliefs, and behavior regarding dehorning dairy calves. As little research has addressed this question, a qualitative, theory-building approach was used and the theory of planned behavior was used as a conceptual framework to guide data collection and analysis. In-depth, semi-structured interviews were undertaken with 15 extensionists working in Santa Catarina, Brazil, to examine their role in the adoption and rejection of pain-mitigation strategies at dehorning. The interview transcripts were free coded, identifying 9 major themes within and across interviews. Transcribed interview responses were then coded to constructs in the theory of planned behavior. The themes and constructs that emerged through analysis of the interview responses were combined to develop a conceptual model of extensionists' beliefs, attitudes, and behavior toward recommending protocols for dehorning aimed at minimizing pain. The extensionists interviewed believed that it was necessary to dehorn all dairy replacement heifers. Despite being aware of methods to minimize pain during and after dehorning, all of the interviewees recommended or used the hot cautery method, with no pain control. This method was described as the most effective, cheapest, safest, and fastest method of dehorning. The majority (12) of interviewees rejected the caustic paste method, citing negative past experiences or unfamiliarity with the method and the belief that the method is less practical and riskier for farmers. More than half of the interviewees did not recognize dehorning as painful or expressed

Received May 28, 2012.

Accepted November 9, 2012.

${ }^{1}$ Corresponding author: mjhotzel@cca.ufsc.br the belief that the pain associated with the procedure did not justify the use of pain control. Although a small number of extensionists (4) recognized potential sources of social pressure to change, including the rejection of pain-inflicting practices by some farmers, the Brazilian general public, and animal-protection societies, they did not identify these factors as a reason to change their existing practices. Interviewees expressed the belief that the adoption of practices to minimize pain and stress, such as dehorning very young calves, using caustic paste and pain control, would increase labor and costs associated with dehorning. Extensionists' negative attitudes toward recommending practices that minimize pain during and after dehorning appear to be embedded in the production-focused political and economic agriculture environment and a lack of education, research, and legislation regarding farm animal welfare. Key words: animal welfare, attitude, theory of planned behavior, education

\section{INTRODUCTION}

The protection of animals in society has become increasingly important in the 20th century, as the industrialization of livestock production has resulted in cheaper and more plentiful animal products while ignoring the negative effects on the welfare of animals (Phillips, 2009). Growing societal concerns for animal welfare is reflected in legal frameworks for ethical standards that have emerged in many countries since the $1950 \mathrm{~s}$ and 1960s in response to the industrialization of animal production (Fraser, 2008; Rollin, 2010). The emergence of societies to protect animal welfare (Phillips, 2009), increased activism, and media coverage of the treatment of animals (Buller and Morris, 2003; Rollin, 2010) have prompted regulatory changes aimed at protecting animals (Centner, 2010).

Global regulatory initiatives in animal welfare (Fraser, 2008) have resulted in several animal welfare-related policies in Brazil. For instance, after Brazil embraced the World Organization for Animal Health (OIE) Farm Animal Welfare initiative (Bayvel, 2004), the animal 
welfare debate took on a new importance in the Brazilian agricultural sector (http://www.agrocim.com.br/ noticia/Suinocultura-precisa-de-legislacao-especifica. html) and animal welfare education increased in universities (Molento and Calderón, 2009). Animalprotection organizations, which have played a key role in publicizing issues and encouraging reform in industrialized countries (Fraser, 2008), sought improvements in the welfare of farm animals in Brazil (http:// www.confinamentoanimal.org.br/conteudos-on-line/ animais-de-producao.asp and http://www.wspabrasil. org/trabalhoWSPA/animaisproducao/default.aspx). In 2008, the Ministry of Agriculture, Livestock and Food Supply (Brasília, Brazil) enacted legislation recommending general procedures regarding the welfare of animals of economic interest (Brasil, 2008). To adjust to this new animal welfare-focused reality, animal industries in Brazil may need to implement changes in husbandry practices aimed at improving welfare outcomes (Poletto and Hötzel, 2012). In particular, changes to current invasive, surgical procedures carried out on farm may be required, as such practices cause pain and distress to animals and "are likely the most contentious of all animal welfare issues" (Rushen et al., 2008).

Several invasive, surgical procedures are used in dairy farming, including extra teat removal, castration, and dehorning. In modern dairy systems, dehorning calves is considered essential to improve the ease of handling of adult cows and to prevent injuries to other animals and handlers (Phillips, 2002; Rushen et al., 2008). Recent research shows that many dairy calves are dehorned with heat cautery, later than the recommended age and with insufficient or no pain control (Vasseur et al., 2010; Gottardo et al., 2011). In a recent survey of 124 family dairy farmers in the southern state of Santa Catarina, it was found that $95 \%$ dehorned dairy calves were kept for herd replacement and $91 \%$ used the heat cautery method at a median calf age of 5 mo, without pain control (Costa et al., 2011).

Results of the survey suggested that the adoption of production-focused animal husbandry practices is influenced by extension programs. Farmers identified the adoption of modern practices introduced by extensionists (e.g., milking parlor improvements, increases in herd size, and rotational pasture management), which have necessitated the dehorning of dairy calves (Cardoso et al., 2012). Given the influence that extension programs have had on the adoption of animal husbandry practices such as dehorning, attempts to improve the animal welfare outcomes of these practices will require a greater understanding of the role of extensionists.

Agricultural extension is seen as the science of promoting voluntary behavioral change within social systems (Röling, 1988) and it is typically assumed that failure to change behavior is the fault of the farmer, not the extensionist (Ruttan, 1996). As such, adoption research has focused on the beliefs, attitudes, and behavior of farmers in an effort to determine why changes do or do not occur. For example, recent studies have investigated the factors that influence the adoption of pain control for calf dehorning by farmers (Misch et al., 2007; Gottardo et al., 2011), as well as the attitudes of veterinarians who may use pain control for surgical procedures in cattle (Huxley and Whay, 2006; Hewson et al., 2007; Laven et al., 2009; Fajt et al., 2011). However, little is known about the role that the beliefs, attitudes, and behavior of extensionists play in influencing changes in practice.

According to Ajzen (1991), behavior is influenced by a person's beliefs and attitudes toward a target behavior. To understand the behavior of extensionists toward recommending dehorning practices that minimize pain and suffering during and after dehorning, we need to examine their beliefs and attitudes toward these practices. The aim of this study was to investigate Brazilian extensionists' beliefs and attitudes toward pain mitigation for dehorning.

\section{MATERIALS AND METHODS}

As little research has been undertaken in this area, a qualitative, theory-building approach was used to explore Brazilian extensionists' beliefs and attitudes toward pain mitigation for dehorning. The theory of planned behavior (TPB; Ajzen, 1991) was used as an explicitly specified conceptual framework to guide data collection and analysis (Kochen, 1985; Miles and Huberman, 1994). The a priori specification of TPB constructs in the research design helped to provide a "firmer empirical grounding for the emergent theory" (Eisenhardt, 1989, page 536). The TPB, presented in Figure 1, posits that an individual has a set of beliefs about a new behavior and their evaluation of these beliefs results in an attitude, either positive or negative, toward the behavior (Ajzen and Fishbein, 1980). This positive or negative attitude leads to the formation of an intention to perform or not perform the target behavior, which, in turn, leads to the performance or nonperformance of the target behavior (Ajzen and Fishbein, 1980). Subjective norms are posited as antecedents to behavioral intentions (Ajzen, 1991) and perceived behavioral control is posited as an antecedent to behavioral intentions and actual behavior (Ajzen, 1991). Subjective norms are the product of the individual's perceptions of the expectations of important social referents combined with their motivation to comply with these perceived expectations (Ajzen, 1991). 


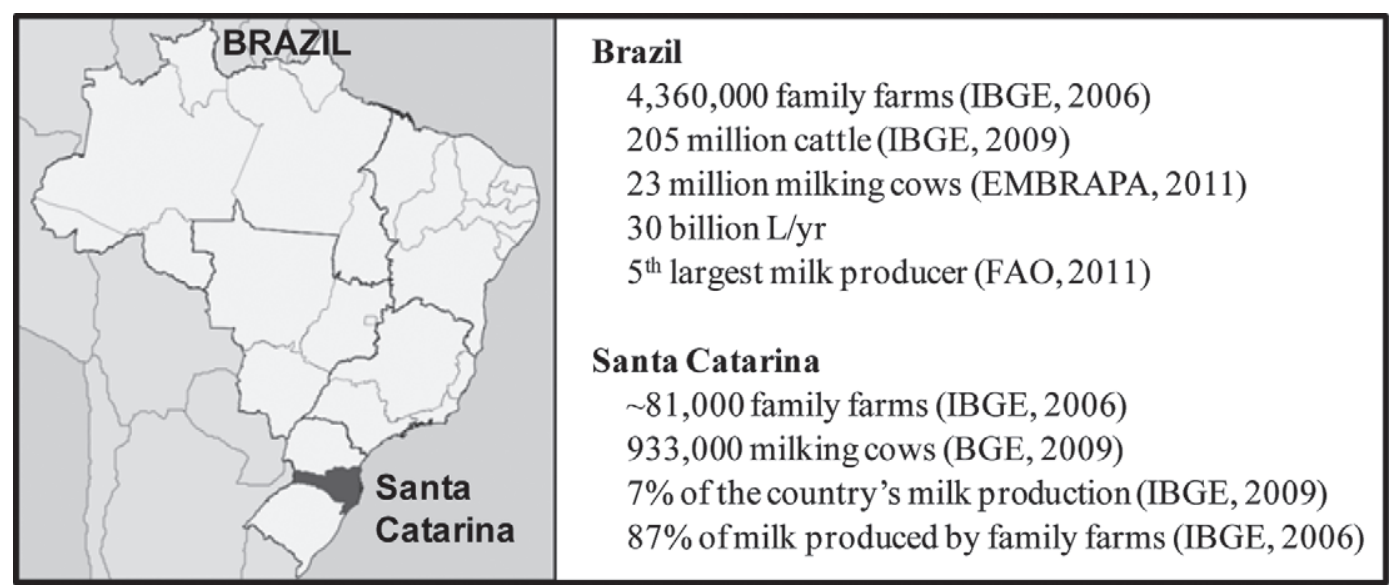

Figure 1. Map indicating the study region, and some socioeconomic contextualization of the local milk production.

Perceived behavioral control is the perceived degree of control the individual feels they have over performing the target behavior (Ajzen, 1991). The TPB was used as a theoretical framework to study extensionists' beliefs, attitudes, intentions, and behavior toward recommending protocols for dehorning calves aimed at minimizing pain because of its successful use in the prediction of behavioral intentions in an animal agricultural context (e.g., Coleman et al., 2003; Keong and Hirst, 2010; Läpple and Kelley, 2010).

In-depth interviews, structured around a free-response format for belief elicitation, as recommended by Ajzen and Fishbein (1980), were used to collect data from extensionists working in the dairy industry in Santa Catarina, Brazil. The in-depth interviews were designed to enable participants to openly discuss their own beliefs, attitudes, and behavior toward recommending practices for dehorning dairy calves on farm (Robson, 1993).

Standard practice in qualitative research dictates that the number of interviews required is reached once no new information is elicited from interviews (Robson, 1993). In the present study, data saturation was reached after 15 interviews with extensionists. Interviewees (14 males and 1 female) were recruited using a snowball technique whereby initial interviewees were asked to recommend colleagues who worked with dairy farmers. The selection criteria for interviewees were that they worked as extensionists with dairy family farmers in the northwest region of Santa Catarina, Brazil (see Figure 2 ). Of the 15 interviewees, 5 were agronomists (referred to as Agr 1 to Agr 5), 4 veterinarians (referred to as Vet 1 to Vet 4 ), and 6 were agricultural technicians (referred to as AT 1 to AT 6). Half of the interviewees worked for dairy cooperatives and half for public state or municipal extension bodies. All of the interviewees received their degrees from Universities and colleges in southern Brazil. The average age of participants was 33 yr (ages ranged from 22 to $49 \mathrm{yr}$ ) and all participants, except 1 , were born and raised in rural municipalities in southern Brazil. The extensionists interviewed worked with family farmers in the northwest region of Santa Catarina. Family famers in this region are predominantly of European descent, mostly Italians and Germans. In this region, the majority of family farms have traditionally kept cows for their own consumption and, in the last few decades, some have become dairy producers (Chaddad and Jank, 2006), though many are pluriactive (Cazella et al., 2009). Milk in this region is produced using pasture-based systems, with varying supplementation, with herds of, on average, 15 lactating cows (ICEPA, 2011; Costa et al., 2013). Although participants did not specify whom in the family they targeted the majority of their communication with, it is clear from the literature that extension activities in the region are targeted at male farmers. This is especially evident in regard to courses and seminars, which are attended by the father, as the mother is busy with domestic work (Paulilo et al., 2000; Cardoso, 2012; Costa et al., 2013).

Interviews were conducted in person at a time suitable for each interviewee. The interviews lasted around $40 \mathrm{~min}$ and were carried out by the same interviewer to ensure consistency. All interviews were tape recorded, with interviewees being made aware when recording commenced and finished. Interviewees were asked open-ended questions about their beliefs, attitudes, and behavior toward dehorning practices used on farm. In addition to free-response format questions designed to elicit beliefs and behaviors toward dehorning and pain 


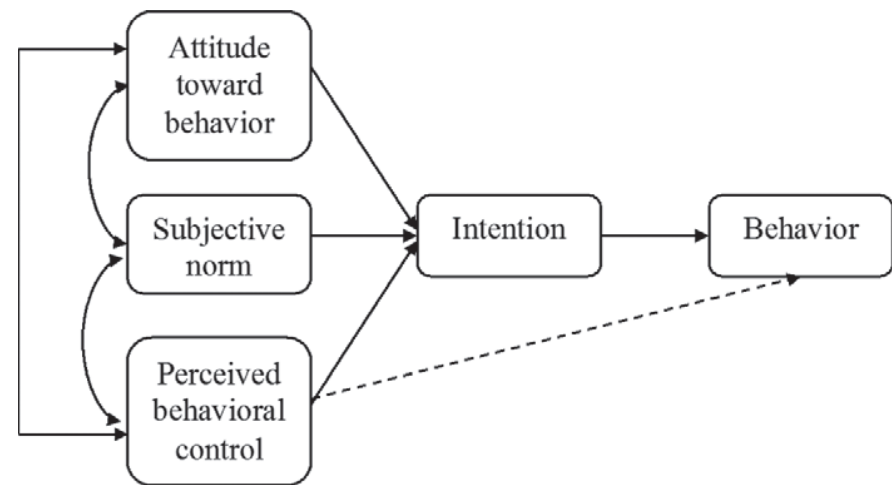

Figure 2. The theory of planned behavior (Ajzen, 1991). Reprinted from Organizational Behavior and Human Decision Processes, Vol. 50 , I. Ajzen, The theory of planned behavior, pages 179-211, Copyright (1991), with permission from Elsevier.

relief, interviewees were also asked questions designed to elicit antecedents to behavioral beliefs, control beliefs and social norms. For example,

- Why do you believe that dairy cattle need to be dehorned or disbudded?

- Why do you recommend [insert practice used] dehorning or disbudding practice(s) to your famer clients?

- Why do you recommend that dairy cows are dehorned or disbudded at [insert age recommended] age?

- What do you think your colleagues, farmer/ clients, and members of the public think about dehorning and pain control?

- Describe how your farmer clients respond to your recommendations about dehorning or disbudding.

The in-depth interviews were carried out and transcribed in Portuguese and then translated into English by the first author, who is fluent in both languages. The interview transcripts resulted in over 2,000 lines of text. Coding and thematic analysis of the translated transcripts were carried out by the authors in 3 stages. First, the interview transcripts were free coded to identify major themes within and across interviews. Nine major themes were identified in the initial analysis of the interview transcripts; these themes (historical context, dehorning beliefs, dehorning timing, sources of information, pain and pain control, farmer and community perceptions, appraisal of farmer perceptions and attitudes, peers and legislation, and extensionist-farmer relationships) are described in detail in the Results section.

Second, transcribed interview responses were coded to constructs in the TPB. Findings were categorized into extensionists' recommendations regarding dehorning, intentions to recommend methods of dehorning and pain relief, attitudes toward dehorning and pain relief, and behavioral, normative, and control beliefs about dehorning and the use of pain relief. Third, contextual factors antecedent to beliefs in the TPB were identified. The themes and constructs that emerged through analysis of the interview responses were combined to develop a conceptual model of extensionists' perceptions, beliefs, and behavior toward recommending protocols for dehorning aimed at minimizing pain.

\section{RESULTS}

\section{Historical Context of Dehorning in Santa Catarina}

Interviewees described their perceptions of the historical context of dehorning in the region; although dehorning was perceived to be a common practice (e.g., ". . . today it is a common procedure for them," Vet 4) it had become so only in the last 2 decades. Participants explained the introduction of dehorning in the region as a response to the conversion of dairying from subsistence to commercial production. The majority of participants expressed positive attitudes toward this change and stated that the need for dehorning in intensive production was driven by changes in cattle genotypes (e.g., "Farmers who work with Holstein cows need to [dehorn]," Vet 4), increases in livestock numbers and daily management activities, the introduction of rotational grazing systems (e.g., "In today's intensive management, it is difficult to work without the dehorning," Vet 3), and the use of housing designed for the supply of concentrated feed and modern milking parlors (e.g., "In those times it was open paddocks . . . the animals had more space ....," AT 6).

Participants equated commercial dairy production and modernization as good farming practice. They expressed positive attitudes toward dehorning in commercial dairying, describing those farmers who dehorn their cattle as good farmers (e.g., "The good producer dehorns their calves," Vet 4).

Participants beliefs about the influence of extension programs on the rapid introduction of this practice were reflected in the agreement of the majority of interviewees $(\mathrm{n}=10)$ that initially farmers were persuaded to accept dehorning ("At the beginning they felt more pity, now they look at it [dehorning] as easier handling," AT 2), sometimes against their values or wishes (e.g., ". . . they had to convince the guys to do something they were not used to do ... ," AT 5). Participants agreed that today little need exists to convince farmers about the need for dehorning, or even to describe or teach the procedure on farm. However, the extent to 
which dehorning has been assimilated into dairy husbandry appeared to vary between regions. In regions where an increase in commercial milk production was more recent, extensionists continued to provide training courses for farmers, and dairy company extensionists undertook dehorning on farm to transfer this practice to farmers.

\section{General Beliefs About Dehorning}

All participants expressed positive attitudes toward dehorning dairy calves and stated that they recommend dehorning to farmers. Only one extensionist expressed a negative attitude toward dehorning, based on the belief that horns are "natural." However, this participant continued to recommend that farmers dehorn their cattle. The majority of participants $(n=12)$ expressed the belief that benefits of dehorning dairy cattle were accrued to both the farmer and the animal. Participants expressed the belief that dehorning helps prevent cows from hurting humans or other cows, reduces intragroup aggression, and enables animals to fit in housing designed for feeding and milking. They stated that these benefits outweighed the costs to the animal (i.e., pain and suffering) incurred by the procedure (e.g., "it is important, it has its advantages: makes handling easier, they occupy less space in the facilities, avoids danger of injury to the animal and handlers . . . animals with horns do not fit in the headlocks," Agr 5). In addition to beliefs expressed about the practical and safety aspects of dehorning, participants also expressed aesthetics as a secondary reason for dehorning dairy cattle (e.g., "the 3 heifers that came from some guys specialized in milk production came dehorned, cute, such beauties!" AT 6).

Participants described cautery with hot iron or electric dehorner, and the caustic paste as the main methods for dehorning. The majority $(\mathrm{n}=14)$ expressed a preference for the cautery procedure using a hot iron. Only one participant expressed a preference for the cautery procedure using the electric device. Participants who preferred the hot iron method expressed the belief that it is the most effective, simple, affordable, fast, convenient, and cheap means of dehorning dairy cattle.

None of the participants recommended caustic paste for dehorning. Twelve interviewees reported negative attitudes toward the use of caustic paste. They expressed the belief that this method caused the animal more pain for a longer period than the hot iron method (e.g., "I do not recommend and do not like it to be done with the paste because it hurts the animal . . . even if with the hot iron ... but with the hot iron is 1 minute and then it is fine," AT 5), and gave examples of their own experiences or observations of unsuccessful procedures, such as regrowth of the horn (e.g., "If you see a cow with a tip of a horn, you know it's because the paste was used," AT 6) or cases in which animals were seriously injured in the eyes or other parts of the body.

Some participants stated the belief that it is difficult to purchase caustic paste locally, whereas others reported that it was freely available to purchase. The research team observed that caustic paste was freely available in the region and that this indicated that it was used by some farmers. The use of caustic paste in the region was further supported by participants stating that farmers had asked them for information on the product and how to use it. For example, one AT reported that several farmers had requested information from him about caustic paste and his opinion of this dehorning method. This participant stated that he advised farmers not to use caustic paste because of his previous negative experiences with the product. Some participants who did not have first-hand experience of using caustic paste expressed the belief that problems, such as horn regrowth and injury, were due to farmers misusing the product, not problems with the product itself (e.g., "Personally I prefer the hot iron because it does not involve risks, as chemicals [do] . . . but with proper care it is efficient, as any other method," Agr 5). Participants' belief that caustic paste could be easily misused underpinned their negative attitudes toward this dehorning method and objection to recommending it to farmers (e.g., "I am against the use of the caustic paste. Because, first, [farmers] have to be careful when applying it and then, if they don't, they can hurt the animal," Vet 1 and "I do not recommend the caustic paste because I cannot follow up the farmers at all times and then he goes by trial and error and much damage can happen," Agr 2).

\section{The Timing of Dehorning}

Participants stated that they advise farmers to dehorn their calves when they are young. Several extensionists reported that they advise farmers to dehorn before the calf is 2 mo old, whereas others did not specify an age limit. The majority of participants (n $=12$ ) explained that they advised farmers to dehorn their cattle early for practical reasons rather than to reduce pain, suffering or postoperative recovery (e.g., "The younger the better; easier to restrain the calf," Agr 5). The most frequently cited reasons for advising farmers on the timing of dehorning emerged under the following 4 subthemes:

- To improve production efficiency by waiting until there are several calves to dehorn, or to do other husbandry practices such as weaning, so that a group of animals could be brought together at the 
same time rather than undertaking procedures individually.

- To improve effectiveness of the procedure by waiting for the appearance of the horn bud for ease of identification.

- To improve the safety of farmers, as the younger the calf, the easier it is to handle and restrain during procedures such as dehorning.

- To reduce costs associated with dehorning, as younger calves do not need to be dehorned by a veterinarian.

\section{Formal Education and Other Sources of Information}

Participants stated that they learned about dehorning and how to dehorn through a combination of formal education and field practice (e.g., "We learn at school, you know, but practice is what teaches you how to adapt it," Agr 2) or solely from field practice (e.g., "I don't remember learning anything at school, it's from the day to day practice . . . ," Agr 1). Five AT said they learned the practice of dehorning in school and had participated in practical demonstrations. However, only 3 of the 9 participants with higher education received specific technical information on the procedure or practical demonstrations on dehorning at University. Eight participants stated that their knowledge on the practice of dehorning came mostly from field practice (e.g., "In school they teach you, but you really learn [dehorning] doing it, because they just teach you the basics," AT 5) and 2 reported that they learned how to dehorn cattle through participation in education programs run by their extension colleagues.

Those participants who reported that they learned the dehorning procedure during their formal education said that they were taught the cautery method using the hot iron, however, a small number were also informed about the use of caustic paste. When asked to recall what they had learned about the use of caustic paste, these participants described the disbudding procedure in accordance with modern literature, with regard to necessary care and the most appropriate age to proceed.

Three of the veterinarians interviewed stated that they learned about issues relating to the welfare and handling of animals during the dehorning process, such as the use of anesthesia and restraining, but not actual dehorning techniques (e.g., "At school you learn more about the general techniques, you know! How to do local and general anesthesia, restraining ....," Vet 1). Only 4 participants out of 15 described having learned about pain control in the dehorning context.

\section{Extensionists' Beliefs Regarding Pain and Pain Control}

The majority of participants expressed the belief that dehorning causes pain to the calves. However, 11 participants considered pain to be short in duration and of low intensity (e.g., ". . . there is no need for pain control, because in reality in hurts very little," AT 3) and only one expressed beliefs to the contrary. As adult cows continue to be dehorned in the region, extensionists used comparisons between adult cows and young heifers to discuss both the pain associated with dehorning and the lack of a need for drugs to prevent or minimize pain in young calves:

". . . the younger animal . . . it feels pain, but much less than an older animal. Or maybe it can feel a little more, but the effects are greater in older than in younger animals," AT 4.

Some participants compared dehorning with other routine invasive procedures to support their beliefs that dehorning causes less stress to the animals than other procedures such as castration and removal of extra teats, or is just one more source of stress. Seven participants stated that they had observed that soon after being dehorned with a hot iron, without pain control, animals showed few changes in behavior. For example, the observation that calves do not stop eating after being dehorned with the hot iron was used to exemplify how little the procedure affects calves:

". . . logically she feels on the moment, but it doesn't affect her much, she does not stop eating," Vet 4.

None of the participants interviewed recommended or made use of pain control and relief, such as local anesthesia, sedation, or analgesia, when dehorning calves. This included those participants who learned about pain relief during their formal education. Only one participant expressed a positive attitude toward the use of pain control for dehorning (e.g., "I think it is necessary [pain control], I do. Actually to do this a person has to be a bandit! We do [dehorn without pain control], but I think it's a crime, the animal suffers a lot," AT 1). In contrast, 8 participants argued that there is no need for pain control, as the amount of pain involved does not justify it (e.g., ". . . of course she feels, but it not such an intense and hurting pain," AT 6). Other reasons given for not recommending or using pain control were the high cost of drugs, increase in time and labor required for the procedure, and the added complication 
and cost factor of requiring a veterinarian to administer pain relief.

"... there is the cost of anesthesia, so we end up doing what is most practical, the conventional... and if you have to wait for the anesthesia to act, you'll spend the whole day . . . then I think really it is because of the time that it's not feasible," AT 1.

\section{Beliefs About Farmers and Community Perceptions}

During the interviews, participants described several beliefs, which they identified as having influenced their attitudes toward dehorning. All participants expressed the belief that the most widely used method of dehorning (i.e., hot cautery with no pain control) is accepted by local dairy farmers. When expressing their beliefs about the use of pain relief for dehorning, some participants stated that those beliefs simply reflected those of the farmers they worked with. They claimed that farmers are not interested in pain relief (e.g., "Farmers don't ask for it [pain relief]," Agr 2) and that farmers' negative beliefs and attitudes toward pain relief prevented them from recommending the use of pharmaceutical drugs to control pain. For example, when asked if he recommends pain control for dehorning, one agronomist stated

"... if [the farmer] has 4, 5, 10 animals to [dehorn] and you start using the sedative and making a lot of things it ends up that the farmer just thinks that this is very expensive and time consuming . .. and then the recovery process is the same ... ," Agr 4.

Further, participants justified their negative attitudes toward the use of pain relief in dehorning to its lack of acceptance and use among agricultural professionals:

“. . . no [colleague] here does this, using anesthesia before and an analgesic after ... what I see is that in fact no one does it and there is no need to do it," Agr 5.

Some described their awareness of opposing opinions in society. For example, 3 extensionists stated that dehorning could be considered ethically objectionable if analyzed from the point of view of people or groups interested in animals (e.g., "I know that many people feel for the animals, because it hurts the animal . . .," AT 2). They expressed a concern that in the future, societal sentiment may result in the prohibition of such practices. One participant argued that it was the role of extensionists to increase farmers' awareness of animal welfare issues (e.g., "We need to bring awareness on animal welfare issues to the farmers," Vet 2).

\section{Extensionists' Appraisal of Farmer Perceptions and Attitudes}

Participants expressed conflicting perceptions of farmers' beliefs and attitudes toward pain and suffering caused by dehorning. Some participants expressed the belief that farmers are concerned about pain and suffering experienced by the animal (e.g., "We [extensionists] do not feel the same because we got used to it, but there are farmers who have pity and refuse to do it, then they call someone else [to dehorn their calves]," AT 2). Others stated that they believed farmers do not believe dehorning causes pain and suffering to the animal (e.g., "The farmers feel that [the animals] do not need it [pain control], that it will soon pass . . . ,"Vet 2). Those participants who agreed that farmers believe dehorning does not cause pain and suffering argued that these beliefs prevented the adoption of pain control on farm (e.g., ". . . the use of anesthetics is not actually feasible because farmers think it is so simple to do [dehorning], that the animal eats right away, it seems not much stressed, that is not something so traumatic ... ," Agr 5).

Participants expressed positive and negative beliefs about farmers' willingness to use of pain control when dehorning if it was offered to them. Some extensionists stated that they believed farmers would not be willing to use pain control if it was offered to them. Participants described several reasons why farmers would reject pain control, such as it being impractical (e.g., "I believe it [pain control] should be used . . . but it's not practical for farmers and they will not do it," Agr 2), expensive (e.g., "my father would, and many others I know too . . . but there are two sides of the coin . . . the economic and the sentimental side," AT 6), and unnecessary (e.g., "There is no need . . . and [farmers] would not accept it, even if it were cheap," AT 2). However, one AT suggested that farmers were not willing to use pain control during and after dehorning because they are not aware of the options available to them and that lack of awareness was, in part, the responsibility of the extensionists:

"So the question is sometimes the fact that the farmer does not know about pain control options . . . some of it is our mistake . . . it is wrong . . . Farmers do care because they raise the animal since its birth, with love ...," AT 6 . 


\section{Perceptions of Peers and Legislation}

All participants agreed that the methods they used and recommended for dehorning (i.e., hot iron cautery without pain control) were widely accepted by the 3 main professions involved in dairy farming extension in the region (i.e., veterinarians, agronomists, and agricultural technicians). Participants expressed the shared belief that disbudding and dehorning is a task to be performed by the farmer. The majority $(\mathrm{n}=10)$ of the interviewees stated that it was either not part of the duties of their job to undertake dehorning, or that they did not have time to do it because of the large numbers of farms they worked with (e.g., "We have many farmers here, then if we did the dehorning we would spend all our time just doing it and still would not be done with it," AT 3).

Some of the agronomists and AT interviewed claimed that that they did not have the necessary knowledge or they were prevented by law to use or prescribe drugs (e.g., "Nobody uses [pain control] around here, even more so because there are no veterinarians," Agr 2). Many participants $(\mathrm{n}=7)$ expressed the belief that regulations restricting the use of drugs to control pain may constrain their adoption on farm. Although some interviewees stated that, by law, only veterinarians should undertake dehorning, few participants agreed or complied with this requirement (e.g., ". . . if you check the law, dehorning is a surgery and should be done by the vets, but in practice this does not happen and it is impracticable," Agr 5). In terms of the use of pain control for dehorning, participants agreed that only veterinarians could prescribe analgesics and use anesthetics:

". . . as an agricultural technician I could not use and do not use drugs for pain control . . . but that's a veterinarian's job; though agricultural technicians can do the disbudding, we cannot use drugs. . . . We do not have the knowledge to use anesthesia; then I ask farmers to call a veterinarian, which is more appropriate," AT 5.

\section{Extensionist-Farmer Relationship}

Eight of the extensionists interviewed stated that building and maintaining a good professional reputation and credibility among farmers was essential for them to earn the trust of farmers and the ability to influence their decisions. According to these participants, building strong, trusting relationships with farmers requires considerable time working within the community and a history of successful experiences on farm:
". . . rural extension is a relationship that has a lot to do with trust. It's something you build over time . . extensionists have to work a lot on this issue of recognition . . . you have to incentive changes in steps, it is a process. It has to be slow and they have to see a return. It is an educational job, quite time consuming, it is long, it is long term," Agr 2.

The belief among extensionists that the hard-won trust of farmers could be easily lost as a result of failures or negative experiences was also evident (e.g., ". . . what I say they sign below and it's like a law. If you do serious work farmers accept you. But it has to be very good, one mistake and it is gone," AT 1). For instance, one agronomist mentioned the history of unsuccessful new ideas in the region, such as escargot and silkworms, as "bad examples" that now hold back the introduction of practice change by extensionists.

Some participants argued that recommendations that were most likely to be adopted by farmers were those with an observable economic return, that do not demand extra labor, and have low risk of failure. These principles seemed to guide their decisions regarding their choice of practices recommended to farmers (e.g., "The arguments mostly used to encourage a producer ... always ends up being the economic [arguments], right?" Agr 3 and "The greatest barrier for them to accept our recommendations is labor. .. Here the cultural issue counts a lot, you may recommend something; if this generates more labor and is not practical they will not adopt it," Agr 2.)

The extensionists interviewed described the difficulties they faced persuading farmers to change their practices. They expressed the belief that their recommendations are not always adopted by farmers who rely on learning from their own experiences when making practice changes:

"I recommend disbudding at 30 days, when the bud comes out, but they used their own timing, they did not take me seriously and did it when they had time. But now they have learnt that the sooner you make it, the easier it is, and with less effects to the animal," AT5.

The extensionists spoke about the need to use different ways to achieve their aim of persuading farmers to adopt their recommendations. Many participants explained that, in the past, extension courses were organized to demonstrate the dehorning procedure for farmers, but these were no longer necessary, as dehorning has become common practice. According to 
participants, dehorning is sometimes mentioned during courses on calf rearing or in one-on-one farm visits when farmers ask for advice on the practice. Some farmers have also been encouraged to become demonstration farms to show successful examples of husbandry practices to other farmers. In addition to education, one-on-one advice and on-farm group demonstration, extension organizations in the region also bring professionals from outside the community to give talks to farmers, as a means of boosting credibility of their own recommendations (e.g., "Because if it is only us saying the same things it is tedious and we cannot convince people, then we brought in outsiders with good reputation in the field," AT 1).

\section{DISCUSSION}

As described in the Results section, participants recommended or supported the use of hot cautery without pain control as the preferred method for dehorning dairy calves, and expressed negative attitudes and beliefs toward recommending dehorning protocols aimed at minimizing pain. Most significantly, the beliefs that underpinned attitudes and subjective norms appeared to be influenced by an underlying belief in the primacy of productivity over all other farming goals, including animal welfare. Figure 3 presents the proposed conceptual model of extensionists' perceptions, beliefs, and behavior toward recommending protocols for dehorning aiming at minimizing pain that emerged from the data. Negative attitudes toward recommending dehorning practices aimed at minimizing pain appeared to be underpinned by beliefs about pain felt by calves at dehorning, about farmers' goals and the nature of the extensionist-farmer relationship. The majority of participants expressed beliefs that dehorning-associated pain is of relatively low magnitude and duration, and that practices to minimize pain increase the labor, time, and cost of dehorning, making them unacceptable to famers. When explaining their beliefs about the magnitude of pain associated with dehorning, and the benefits of practices such as dehorning as young as possible or using pharmacological tools to control pain, participants frequently referred to a trade-off between productivity and animal welfare. They expressed beliefs that farmers do not perceive dehorning as a painful procedure, and that farmers prioritize productivity over animal welfare. Participants believed that their professional peers and farmer-clients approved of their choice of dehorning method, and indicated the belief that they might lose the farmers trust if their recommendations contradicted the farmers' goals. Although some participants recognized that society is interested in animal welfare, this did not influence their decision regarding the choice of method to recommend to farmers. In addition to social influences, a small number of participants expressed the belief that legal barriers preventing the use of pharmaceutical drugs by nonveterinarians impede recommendations to use pain control methods on farm. A strong production-focused agriculture policy and economic environment, and the nascent nature of farm animal welfare as a concern for the policy and education sectors may lie at the base of most of these beliefs.

\section{Contextual Factors}

The underlying belief about the primacy of production goals may have emerged from the productionfocused political and economic environment that has dominated Brazilian agriculture and extension policies since the early 20th century. It was in this agri-political environment that a commercial dairy industry emerged in southern Brazil in the 1960s and 1970s (Schneider and Niederle, 2010). The genesis of commercial, productionfocused extension programs found in the Santa Catarina dairy industry lies in public policies introduced in Brazil in the late 1940s. These public policies, aimed at increasing agricultural production and productivity, included the introduction of public extension programs, which had a significant effect on the agricultural sector in Brazil (Chaddad and Jank, 2006; Martinelli et al., 2010; Schneider and Niederle, 2010). Public extension programs were designed to effect a "technologicallybased transformation" of the Brazilian agricultural sector from family-based subsistence farming to commercial agriculture (Caporal, 1991; Schneider and Niederle, 2010). Attempts to effect a "technologicallybased transformation" of the Brazilian dairy industry has been criticized for excluding small-scale family farms that are unable to follow technological standards aimed at meeting the production and quality demands of large dairy companies dominating the sector (Telles et al., 2008; Clemente and Hespanhol, 2010). In the $1990 \mathrm{~s}$, the Brazilian government attempted to address the limitations of the "technologically-based" approach to transforming the agricultural sector. These reforms prompted moves to programs aimed at supporting the sustainability of small family farms (Chaddad and Jank, 2006; Telles et al., 2008). Our findings suggest that small family farms in the Santa Catarina region commenced commercial milk production with the support of government extension programs that prioritized production-focused goals. As such, extensionists working with this farming population introduced dehorning as a good farming practice and did not recommend pain mitigation. Despite recent changes to government extension policies aimed at stimulating sustainable 


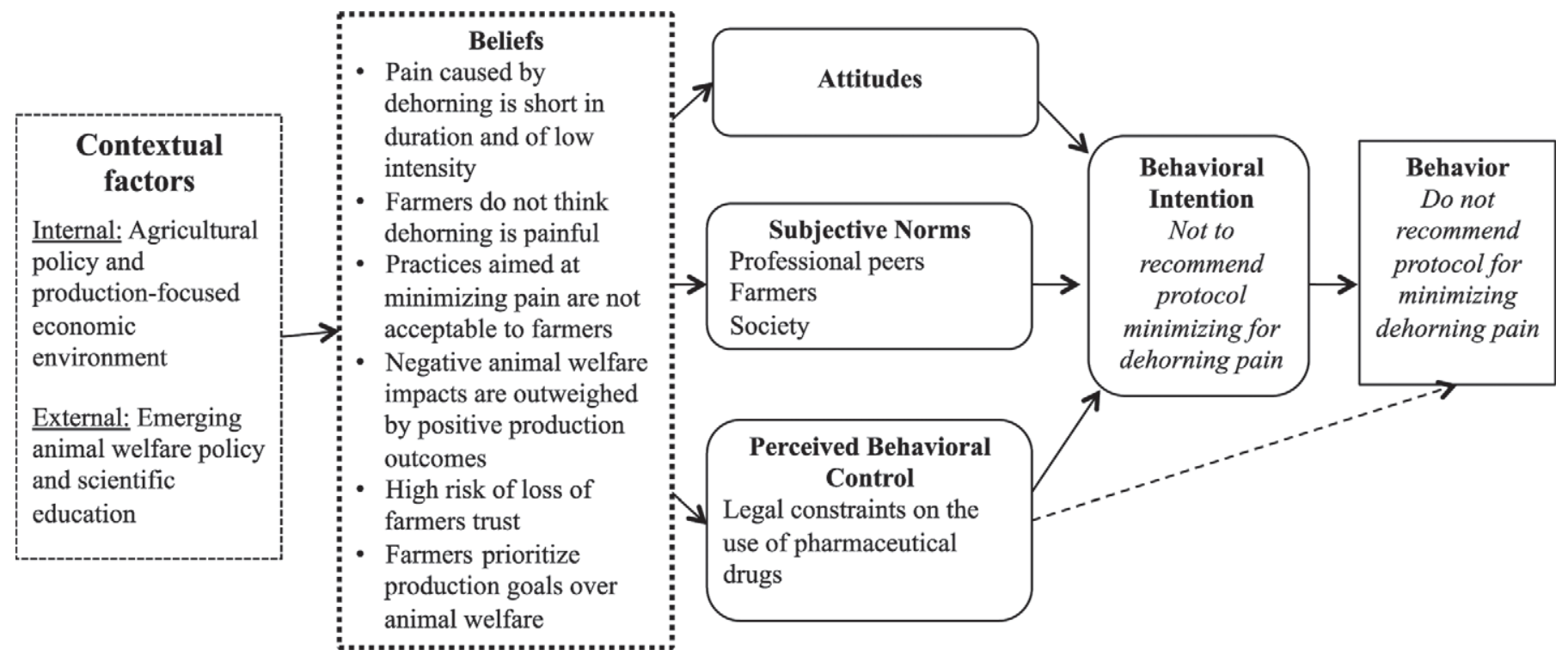

Figure 3. Summary of interview findings.

agricultural practices, including animal welfare, extensionists working with small family dairy farms continue to promote practices that have negative animal welfare outcomes, such as dehorning without pain mitigation. Given these findings and those reported by Karam and de Freitas (2008), it appears that although the explicit aim of dairy extension programs in the State of Santa Catarina is to achieve social, environmental, and ethical sustainability, in reality, extensionists provide support to farmers aimed at helping them meet growing demand for milk produced efficiently and at a low cost of production.

\section{Attitudes and Beliefs}

Participants expressed the belief that calves do not show behavioral changes after dehorning. This belief supported their assertion that hot-cautery dehorning causes little pain or stress to calves. However, these beliefs are not supported by empirical evidence, indicating poor training of these extensionists. Research shows that calves display behavioral responses indicative of pain after dehorning, such as head shaking and ear flicking (Faulkner and Weary, 2000) and reduced feed intake (Duffield et al., 2010), which can result in weight loss (Faulkner and Weary, 2000), which can be reduced or eliminated with the use of sedation, anesthesia, or analgesia (Faulkner and Weary, 2000; Vickers et al., 2005; Stilwell et al., 2009). Participants' beliefs that calves do not perform behaviors indicative of pain after dehorning may also be a result of limited opportunities for extensionists to observe calves after dehorning (Laven et al., 2009), as changes in behavior are known to persist for $24 \mathrm{~h}$ or longer. Additionally, cattle tend to demonstrate limited overt indications of pain, a behavior strategy that evolved to avoid attack from predators (Huxley and Whay, 2006), which may hinder the identification and assessment of pain in animals, especially by untrained observers.

Understanding and addressing the extensionists' ability to identify pain responses to dehorning is required to change their beliefs about pain caused by dehorning, as the inability to recognize the level of pain that cattle are suffering is a barrier to use of pain control (Huxley and Whay, 2006). Research has found that assigning lower pain scores to cattle is associated with lower frequency of the use of pain control by veterinarians for pain-inducing procedures (Hewson et al., 2007; Fajt et al., 2011). As beliefs are antecedents of attitudes (Ajzen and Fishbein, 1980; Ajzen, 1991), education aimed at influencing the beliefs of extensionists about the capacity of farm animals to feel pain and ways to prevent and relieve pain is required to change attitudes toward the need for pain control for dehorning.

The gap between scientific research and the technological development of methods to minimize pain associated with dehorning, and the education and field practice of extensionists found in the present study has been described in Whay and Huxley (2005). Inadequate or insufficient training of extensionists in animal welfare science has been identified as a barrier to changing beliefs about animal welfare issues (Heleski et al., 2004). Education in animal welfare science is growing, but still limited in universities in Latin-American countries, including Brazil, where animal welfare science education is a relatively recent phenomenon (Molento and Calde- 
rón, 2009). Despite the introduction of animal welfare science programs in universities in Latin-America in the last 30 yr (Molento and Calderón, 2009; Tadich et al., 2010 ), only around $56 \%$ of veterinary and animal science programs in Brazil teach animal welfare, and only $33 \%$ as a compulsory unit (Molento, 2008). Furthermore, because pain management training is classically covered in courses such as anesthesiology or pharmacology, the issue is often not part of animal welfare courses. This issue, which is not limited to Brazil (e.g., Hewson et al., 2005), means that non-veterinarian extensionists may not receive training in pain management.

The belief expressed by interviewees that farmers would not accept recommendations to adopt dehorning protocols aimed at minimizing pain appears to be embedded in the belief that farmers do not perceive dehorning to be painful to calves. These findings reflect those reported in studies of veterinarians' perceptions of farmers' beliefs and attitudes toward pain and pain control (e.g., Heleski et al., 2004; Whay and Huxley, 2005; Thomsen et al., 2010). Additionally, some participants asserted that farmers would not be willing to adopt protocols aimed at minimizing pain, as these would be considered unacceptable due to increases in cost, time, and labor. The extensionists' descriptions of farmer's beliefs and goals were generalized across all farmers. However, the existence of variation in farmers' attitudes toward animal welfare has been identified in research undertaken in the United States and Italy, which reported variations in farmers' ratings of pain associated with dehorning in calves (e.g., Hoe and Ruegg, 2006; Gottardo et al., 2011). Similar levels of variation have been identified in farmers' attitudes toward the use of pain control. For example, whereas most farmers in a UK survey identified the cost of analgesia as a barrier for its use, $36 \%$ did not agree (Huxley and Whay, 2007). In a similar study, more than half of the 639 Italian farmers surveyed declared that they would be willing to pay for pain control for dehorning their calves (Gottardo et al., 2011). Half of the 35 farmers interviewed in the same region where the present study was carried out expressed negative emotions toward pain associated with dehorning, and though none used pain control, some said that they would if they were offered the option (Cardoso et al., 2012), which was also suggested by one interviewee. Altogether, this suggests that discrepancies between extensionists' beliefs may result from experiences with different types of farmers. It is also likely that, at least in some cases, farmers would accept using pain control if offered by extensionists.

\section{Subjective Norms and Beliefs}

In the opinion of interviewees, because farmers are not motivated to adopt practices to improve the welfare of their animals, recommending such practices would result in them losing the farmer's trust. This appraisal of farmers' beliefs may be biased by participants' own production-oriented attitudes toward farming. This conclusion is supported by studies that show that veterinarians tend to overestimate the farmers' emphasis of production and financial performance over animal welfare (Kristensen et al., 2008), and to generalize the belief that economic conditions are the main barrier to improving animal welfare on farm, despite farmers holding a range of goals and attitudes toward animals (Dockès and Kling-Eveillard, 2006).

Societal concerns about the use of painful husbandry practices on farm was raised by only a few participants, who dismissed these concerns as irrelevant in the context of animal production. However, the increasing awareness of farming systems and the impact on animal welfare among the Brazilian public [World Society for the Protection of Animals (WSPA) campaign; see: http://e-activist.com/ea-action/action?ea.client. id=24\&ea.campaign.id=13047\&ea.tracking.id=offline] and internationally suggest an emerging scenario of growing social pressure to change husbandry practices associated with poor animal welfare in the future (Poletto and Hötzel, 2012). Changes in societal attitudes toward the welfare of production animals and pressure from the international community through organizations such as the Food and Agriculture Organization of the United Nations (FAO) and World Organization for Animal Health have already influenced Brazil to prepare for the introduction of specific legislation on animal welfare (Brasil, 2008).

Nonetheless, it appears that potential changes to legislation and pressure from the local and international community have had little impact to date on extension programs in the Brazilian dairy sector. For these to have an impact, greater awareness of changing societal norms about animal welfare and a deeper understanding of the implications for the sector are needed to challenge existing beliefs and attitudes. However, such societal pressures may not be enough to influence the behavior of extensionists, if they believe that dehorning protocols minimizing pain conflict with farmers' production goals. Political and economic support for improved animal welfare embedded in animal production goals, allied to education and training in livestock welfare issues is required.

\section{Perceived Behavioral Control}

In Brazil, it is a legal requirement for veterinarians to carry out the dehorning procedure (CFMV, 2008) and non-veterinarians are not allowed to prescribe pharmacological drugs for pain relief under the legislation. 
Although most participants expressed the belief that farmers should dehorn their own calves and, therefore, did not comply with current regulations, some participants identified the legislation as a barrier to the promotion methods of dehorning that minimize pain for on-farm use. To address this issue, in other countries, it has been suggested that routine dehorning services be conducted by trained technicians through a veterinary practice (Duffield, 2008), or employing veterinarians to serve small farms at a community level (Stafford and Mellor, 2011). Creating mechanisms, for example, to allow trained technicians to use drugs for pain control and carry out invasive procedures, may be necessary for the widespread adoption of protocols for dehorning that include pain control.

\section{CONCLUSIONS}

The negative attitudes of extensionists toward recommending practices that minimize pain during and after dehorning appear to be embedded in the production-focused political and economic agriculture environment, the still emerging animal welfare debate in Brazil, and a lack of teaching, research, legislation, and the enforcement of existing regulations and standards on animal welfare. Advancement of the animal welfare debate in the farming context is a necessary first step in working toward changing extensionists' attitudes toward pain experienced by animals as a result of invasive procedures. Advancing the animal welfare debate requires public awareness and engagement in animal welfare issues in animal production with the aim of increasing pressure on agribusiness, producers, and legislators to improve animal welfare. Education and legislation targeted at agribusiness and government extension providers is also necessary to work toward changing extensionists' attitudes toward pain experienced by animals during invasive procedures and the animal welfare benefits of using pain relief. However, findings from this study are supported by others carried out in industrialized countries to suggest that more than education and explicit animal welfare legislation is needed for extension to have a positive impact on the adoption of methods of dehorning aimed at minimizing pain. Agricultural and extension policy and practice need to change in ways that allow incorporating the ethical treatment of animals in the concept of good farming. Similarly, it has been proposed that agri-environmental policy goals could be better achieved if they were culturally sustainable, in the sense of "becoming embedded within farming cultures" (Burton and Paragahawewa, 2011). This approach would eliminate the risk perceived by extensionists that promoting a practice that is in contradiction with farmers' perceived goals may lead to loss of credibility and trust of farmers, which, in the opinion of Barr (2011), is a justified belief.

\section{ACKNOWLEDGMENTS}

M. J. Hötzel was funded by Conselho Nacional de Desenvolvimento Científico e Tecnológico (CNPq, Brasília, Brazil; Proc. 200792/2011-3). The authors acknowledge the technical assistance of Clarissa S. Cardoso and Aurilédia B. Teixeira (both of UFSC, Brazil), and Daniel M. Weary (University of British Columbia, Canada), and 2 anonymous reviewers for their valuable comments for improving the manuscript.

\section{REFERENCES}

Ajzen, I. 1991. The theory of planned behavior. Organ. Behav. Hum. Dec. 50:179-211.

Ajzen, I., and M. Fishbein. 1980. Understanding Attitudes and Predicting Social Behavior. Prentice-Hall, Englewood Cliffs, NJ.

Barr, N. 2011. I hope you are feeling uncomfortable now: Role conflict and the natural resources extension officer. Pages 129-140 in Changing Land Management: Adoption of New Practices. D. J. Pannell and F. Vanclay, ed. CSIRO Publishing, Collingwood, VIC, Australia.

Bayvel, A. C. D. 2004. Science-based animal welfare standards: The international role of the Office International des Épizooties. Anim. Welf. 13:S163-S169.

Brasil. 2006. Presidência da República, Casa Civil. Lei No. 11.326, de 24 de julho de 2006. Diário Oficial da União, Brasília, DF, Brazil.

Brasil. 2008. Ministério da Agricultura, Pecuária e Abastecimento. Instrução Normativa No. 56, de 6 de novembro de 2008. Diário Oficial da União, Brasília, DF, Brazil.

Buller, H., and C. Morris. 2003. Farm animal welfare: A new repertoire of nature-society relations or modernism re-embedded? Sociol. Ruralis 43:216-237.

Burton, R. J. F., and U. H. Paragahawewa. 2011. Creating culturally sustainable agri-environmental schemes. J. Rural Stud. 27:95104.

Caporal, F. R. 1991. A extensão rural e os limites à prática dos extensionistas do serviço público. Universidade Federal de Santa Maria, Santa Maria, Brazil.

Cardoso, C. S., C. Uller-Gomez, and M. J. Hötzel. 2012. Decisionmaking of family farmers in Santa Catarina regarding husbandry practices that influence the welfare of dairy cattle. Pages $1-3$ in Proc. XLIX Reunião da Sociedade Brasileira de Zootecnia (SBC). (SBC), Brasilia, DF, Brazil.

Cazella, A. A., P. Bonnal, and R. S. Maluf. 2009. Agricultura familiar: Multifuncionalidade e desenvolvimento territorial no Brasil. Mauad Editora Ltda., Rio de Janeiro, Brazil.

Centner, T. J. 2010. Limitations on the confinement of food animals in the United States. J. Agric. Environ. Ethics 23:469-486.

CFMV (Conselho Federal de Medicina Veterinária). 2008. Conselho Federal de Medicina Veterinária-Resolução No. 877, de 15 de feverio de 2008. Diário Oficial da União, Brasília, DF, Brazil.

Chaddad, F. R., and M. S. Jank. 2006. The evolution of agricultural policies and agribusiness development in Brazil. Choices (N.Y. N.Y.) 21:85-90.

Clemente, E. C., and A. N. Hespanhol. 2010. Restructuring production of dairy cattle: space organization-production on "watershed cows" to "space circuit production". Geonordeste 1:151-174.

Coleman, G. J., M. McGregor, P. H. Hemsworth, J. Boyce, and S. Dowling. 2003. The relationship between beliefs, attitudes and observed behaviours of abattoir personnel in the pig industry. Appl. Anim. Behav. Sci. 82:189-200.

Costa, J. H. C., L. F. Balcão, R. R. Darós, F. Bertoli, and M. J. Hötzel. 2011. Handling of painful procedures in dairy calf management 
in Santa Catarina State, Brazil. Page 101 in Proc. 45th Congr. Int. Soc. Appl. Ethol., Indianapolis, IN

Costa, J. H. C., M. J. Hötzel, C. Longo, and L. F. Balcão. 2013. A survey of management practices that influence production and welfare of dairy cattle on family farms in southern Brazil. J. Dairy Sci. 96:307-317.

Dockès, A. C., and F. Kling-Eveillard. 2006. Farmers' and advisers' representations of animals and animal welfare. Livest. Sci. 103:234-249.

Duffield, T. 2008. Current data on dehorning calves. Pages 25-28 in 41st Annu. Conv. Proc. Am. Assoc. Bovine Pract., Charlotte, NC. Am. Assoc. Bovine Pract., Auburn, AL.

Duffield, T. F., A. Heinrich, S. T. Millman, A. DeHaan, S. James, and K. Lissemore. 2010. Reduction in pain response by combined use of local lidocaine anesthesia and systemic ketoprofen in dairy calves dehorned by heat cauterization. Can. Vet. J. 51:283-288.

Eisenhardt, K. M. 1989. Building theories from case study research. Acad. Manage. Rev. 14:532-550.

EMBRAPA (Empresa Brasileira de Pesquisa Agropecuária). 2011. Produção de leite, vacas ordenhadas e produtividade animal no Brasil, EMBRAPA Gado de Leite - 1980/2010. Accessed Jan. 2012. http://www.cnpgl.embrapa.br/nova/informacoes/ estatisticas/producao/tabela0230.php.

Fajt, V. R., S. A. Wagner, and B. Norby. 2011. Analgesic drug administration and attitudes about analgesia in cattle among bovine practitioners in the United States. J. Am. Vet. Med. Assoc. 238:755-767.

FAO (Food and Agriculture Organization of the United Nations). 2011. FAOSTAT. Accessed May 2012. http://faostat.fao.org/ site/339/default.aspx.

Faulkner, P. M., and D. M. Weary. 2000. Reducing pain after dehorning in dairy calves. J. Dairy Sci. 83:2037-2041.

Fraser, D. 2008. Toward a global perspective on farm animal welfare. Appl. Anim. Behav. Sci. 113:330-339.

Gottardo, F., E. Nalon, B. Contiero, S. Normando, P. Dalvit, and G. Cozzi. 2011. The dehorning of dairy calves: Practices and opinions of 639 farmers. J. Dairy Sci. 94:5724-5734.

Heleski, C. R., A. G. Mertig, and A. J. Zanella. 2004. Assessing attitudes toward farm animal welfare: A national survey of animal science faculty members. J. Anim. Sci. 82:2806-2814.

Hewson, C. J., E. Baranyiová, D. M. Broom, M. S. Cockram, F. Galdino, A. J. Hanlon, L. Hänninen, D. Lexer, D. J. Mellor, C. F. M. Molento, F. O. Ödberg, J. A. Serpell, A. M. Sisto, K. J. Stafford, J. M. Stookey, and P. Waldau. 2005. Approaches to teaching animal welfare at 13 veterinary schools worldwide. J. Vet. Med. Educ. 32:422-437.

Hewson, C. J., I. R. Dohoo, K. A. Lemke, and H. W. Barkema. 2007. Factors affecting Canadian veterinarians' use of analgesics when dehorning beef and dairy calves. Can. Vet. J. 48:1129-1136.

Hoe, F. G. H., and P. L. Ruegg. 2006. Opinions and practices of Wisconsin dairy producers about biosecurity and animal well-being. J. Dairy Sci. 89:2297-2308.

Huxley, J. N., and H. R. Whay. 2006. Current attitudes of cattle practitioners to pain and the use of analgesics in cattle. Vet. Rec. 159:662-668

Huxley, J. N., and H. R. Whay. 2007. Attitudes of UK veterinary surgeons and cattle farmers to pain and the use of analgesics in cattle. Cattle Pract. 15:189-193.

IBGE (Instituto Brasileiro de Geografia e Estatística). 2006. Ministério do Planejamento, Orçamento e Gestão, Brazil. Instituto Brasileiro de Geografia e Estatística. Censo Agropecuário 2006. Accessed Jan. 2012. http://www.ibge.gov.br/home/estatistica/economia/ agropecuaria/censoagro/default.shtm.

IBGE (Instituto Brasileiro de Geografia e Estatística). 2009. Ministério do Planejamento, Orçamento e Gestão, Brazil. Accessed Jan. 2012. http://www.ibge.gov.br/home/estatistica/economia/ ppm/2009/tabelas_pdf/tab01.pdf.

ICEPA (Instituto de Planejamento e Economia Agrícola de Santa Catarina). 2011. Síntese Anual da Agricultura de Santa Catarina 2010/2011. Accessed Jan. 2012. http://cepa.epagri.sc.gov.br/.
Karam, K. F. and L. A. S. de Freitas. 2008. Pesquisa, extensão e aprendizagem participativa-PEAP: subsídios teórico-metológicos.

Keong, Y. O., and G. Hirst. 2010. An empirical integration of goal orientation and the theory of planned behaviour: Predicting innovation adoption behaviour. Int. J. Entrepreneurship Innov. 11:5-18.

Kochen, M. 1985. Are MIS frameworks premature? J. Manage. Inf. Syst. 2:92-100.

Kristensen, E., S. Østergaard, M. A. Krogh, and C. Enevoldsen. 2008. Technical indicators of financial performance in the dairy herd. J. Dairy Sci. 91:620-631.

Läpple, D., and H. Kelley. 2010. Understanding farmers' uptake of organic farming: An application of the theory of planned behaviour. Proc. 84th Annu. Conf. Agric. Econ. Soc. http://purl.umn. edu/91949.

Laven, R. A., J. N. Huxley, H. R. W. Hay, and K. J. Stafford. 2009 Results of a survey of attitudes of dairy veterinarians in New Zealand regarding painful procedures and conditions in cattle. N. Z. Vet. J. 57:215-220.

Martinelli, L. A., R. Naylor, P. M. Vitousek, and P. Moutinho. 2010. Agriculture in Brazil: Impacts, costs, and opportunities for a sustainable future. Curr. Opin. Environ. Sustainability 2:431-438.

Miles, M. B., and A. M. Huberman. 1994. Qualitative Data Analysis: A Sourcebook of New Methods. Sage Publications, London, UK.

Misch, L. J., T. F. Duffield, S. T. Millman, and K. D. Lissemore. 2007. An investigation into the practices of dairy producers and veterinarians in dehorning dairy calves in Ontario. Can. Vet. J. 48:1249-1254.

Molento, C. F. M. 2008. Animal welfare teaching in the veterinary medicine and animal science programs. Ciência Veterinária nos Trópicos 11:6-12.

Molento, C. F. M., and N. Calderón. 2009. Essential directions for teaching animal welfare in South America. Rev. Sci. Tech. 28:617-625.

Paulilo, M. I., A. B. Grandi, and M. M. Silva. 2000. Mulher e atividade leiteira: A dupla face da exclusão. Cadernos de Pesquisa PPGSP/ UFSC 21:16-28.

Phillips, C. 2002. Cattle Behaviour and Welfare. 2nd ed. Blackwell Science Ltd., Oxford, UK.

Phillips, C. 2009. The welfare of animals: The silent majority. Animal Welfare. No. 8. Springer, Brisbane, QLD, Australia.

Poletto, R., and M. J. Hötzel. 2012. The five freedoms in the global animal agriculture market: Challenges and achievements as opportunities for the present and future. Anim. Front. 2:22-30.

Robson, C. 1993. Real World Research: A Resource for Social Scientists and Practitioner-Researchers. Blackwell, Oxford, UK.

Röling, N. G. 1988. Extension Science: Information Systems in Agricultural Development. Cambridge University Press, Cambridge, UK.

Rollin, B. E. 2010. Why is agricultural animal welfare important? The social and ethical context. Pages 21-31 in Improving Animal Welfare: A Practical Approach. T. Grandin, ed. CAB International, Cambridge, MA.

Rushen, J., A. M. de Passillé, M. A. G. von Keyserlingk, and D. M. Weary. 2008. The Welfare of Cattle Animal Welfare and Nutrition. Springer, Dordrecht, the Netherlands.

Ruttan, V. W. 1996. What happened to technology adoption-diffusion research? Sociol. Ruralis 36:51-73.

Schneider, S., and P. A. Niederle. 2010. Resistance strategies and diversification of rural livelihoods: The construction of autonomy among Brazilian family farmers. J. Peasant Stud. 37:379-405.

Stafford, K. J., and D. J. Mellor. 2011. Addressing the pain associated with disbudding and dehorning in cattle. Appl. Anim. Behav. Sci. 135:226-231.

Stilwell, G., R. Campos de Carvalho, M. S. Lima, and M. D. Broom. 2009. Effect of caustic paste disbudding, using local anaesthesia with and without analgesia, on behaviour and cortisol of calves. Appl. Anim. Behav. Sci. 116:35-44.

Tadich, N. A., C. F. M. Molento, and C. B. Gallo. 2010. Teaching animal welfare in some veterinary schools in Latin America. J. Vet. Med. Educ. 37:69-73. 
Telles, T. S., J. M. Ueda Tanaka, and T. Pellini. 2008. Household farmers: Dairy production as a locus of public policies in Paraná State, Brazil. Semina: Ciências Agrárias 29:579-590.

Thomsen, P. T., M. Gidekull, M. S. Herskin, J. N. Huxley, A. R. Pedersen, B. Ranheim, and H. R. Whay. 2010. Scandinavian bovine practitioners' attitudes to the use of analgesic in cattle. Vet. Rec. $167: 256-258$

Vasseur, E., F. Borderas, R. L. Cue, D. Lefebvre, D. Pellerin, J. Rushen, K. M. Wade, and A. M. Passillé. 2010. A survey of dairy calf management practices in Canada that affect animal welfare. J Dairy Sci. 93:1307-1315.

Vickers, K. J., L. Niel, L. M. Kiehlbauch, and D. M. Weary. 2005. Calf response to caustic paste and hot-iron dehorning using sedation with and without local anesthetic. J. Dairy Sci. 88:1454-1459.

Whay, H. R., and J. N. Huxley. 2005. Pain relief in cattle: A practitioner's perspective. Cattle Pract. 13:81-85. 